Marshall University

Marshall Digital Scholar

Biological Sciences Faculty Research

Biological Sciences

Fall 11-2006

\title{
Ethyleneproduction as an indicator of stress conditions in hydroponically-grown strawberries
}

Justin D. Hogan

Elizabeth E. Murray

Marcia Harrison-Pitaniello PhD

Marshall University, harrison@marshall.edu

Follow this and additional works at: http://mds.marshall.edu/bio_sciences_faculty

Part of the Biology Commons, and the Food Science Commons

\section{Recommended Citation}

Hogan, J.D., Murray, E.E. and Harrison, M.A., 2006. Ethylene production as an indicator of stress conditions in hydroponically-grown strawberries. Scientia Horticulturae, 110(4), pp.311-318.

This Article is brought to you for free and open access by the Biological Sciences at Marshall Digital Scholar. It has been accepted for inclusion in Biological Sciences Faculty Research by an authorized administrator of Marshall Digital Scholar. For more information, please contact zhangj@marshall.edu, martj@marshall.edu. 


\title{
Ethylene production as an indicator of stress conditions in hydroponically-grown strawberries
}

\begin{abstract}
As a soilless system, hydroponics eliminates competing weeds and soil-born pests while conserving water and providing conditions that can be quickly altered to suit specific crops. However, stressinduced physiological conditions may arise within the system from factors such as mechanical injury, pests, or inconsistent nutrient flow rates that result in some plants receiving too much or too little water. Most abiotic stress conditions result in increased production of the plant hormone ethylene. High levels of ethylene inhibit growth, cause premature ripening, and induce the onset of senescence, potentially reducing the productivity of hydroponically-grown crops. In this study, we demonstrate that assessing ethylene levels from leaves of hydroponically-grown strawberry plants can be used as an early indicator of stress conditions. Our results demonstrate that there is no significant correlation between ethylene production and temperatures ranging from 15 to $37^{\circ} \mathrm{C}$ or with light intensities ranging from 63 to $1500 \mu \mathrm{mol} \mathrm{m}-2 \mathrm{~s}-1$. However, an increase in ethylene production tended to be positively correlated with sampling time; levels were higher during midday compared to early morning or later afternoon. The daily ethylene fluctuations under greenhouse conditions due to sampling time, light intensity, or temperature changes were not significantly high enough to indicate stress conditions. Overall, three system analyses showed altered ethylene production in plants farthest from the pump supplying the nutrient solution. This effect was interpreted to be caused by excess accumulation of nutrient solution around the plant roots, causing increased ethylene production in the leaves. Our results indicate that different watering patterns, manifested as pump pressure or drainage control, was the more difficult component to control in the design of these hydroponic systems. For example, in one system, an increase in ethylene production was measured for the position farthest from the pump, and resulted in those plants having a lower number of flowers and significantly reduced overall plant radii relative to the system average. In a separate experiment, plants from trays that had been flooded for $24 \mathrm{~h}$ showed a significant decrease in the plant radii and number of leaves and flowers 1 month after the flooding treatment. We conclude that system-wide ethylene measurements can be used to identify stressed plants within hydroponic systems. This type of analysis would be especially useful as an indicator of general stress conditions no matter the cause, identifying locations that may result in lower plant productivity.
\end{abstract}

Keywords: Ethylene; Hydroponic; Strawberry; Stress; Hypoxia

\section{Introduction}

With the worldwide phaseout of methyl bromide as a soil fumigate, the use of hydroponic systems has rapidly increased as an economic alternative for the growth of many horticulturally-important crops (Environmental Protection Agency, 1997; Carpenter et al., 2000; VanSickle et al., 2000; Federal Register, 2004). As a soilless system, hydroponics eliminates competing weeds and soil-born pests, thus reducing 
the need for pesticides and avoiding toxic residues that may accumulate on plants. In addition, hydroponic cultivation conserves water and provides conditions that can be quickly altered to suit specific crops. However, stress-induced physiological conditions may arise within the system if nutrient flow is inconsistent, resulting in some plants receiving too much or too little water. For example, flooding of root systems causes oxygen deficiency and interferes with nutrient uptake (Urrestarazu and Mazuela, 2005). Therefore, careful management of hydroponic systems becomes an important consideration for reducing stress conditions that negatively impact yield, in order to increase market profitability by decreasing cultivation costs.

Many abiotic stress conditions, including chilling and freezing, high temperature, flooding, drought, chemical damage, radiation, and mechanical perturbation, stimulate ethylene production. High levels of ethylene inhibit growth, cause premature ripening, and induce the onset of senescence, potentially reducing plant productivity (Abeles et al., 1992; Druege, 2006). Stress-induced ethylene is regulated by the production of the ethylene precursor, ACC (1-aminocyclopropane-1-carboxylic acid) (see reviews by Abeles et al., 1992; Druege, 2006). For example, during flooding, oxygen deficiency in plant roots results in increased production of ethylene (Jackson, 2002). Anaerobic conditions in plant roots inhibit the oxygen-requiring enzyme, ACC oxidase, which catalyzes ethylene production from its immediate precursor, ACC. As a result, ACC accumulates in the roots and is then transported by the vascular system to the stems and leaves where it is rapidly converted to ethylene. Anaerobic conditions also stimulate the production of ACC synthesis in the roots, contributing more ACC to be transported to the leaves. Consequently, higher levels of ethylene in leaves can stimulate ACC oxidase synthesis and activity, further increasing ethylene production there. In addition to the effects of flooding on ethylene production, Saltveit and Dilley (1978) report that wound-induced ethylene production increases after a time lag of 16-26 min and proceeds to peak production within $60 \mathrm{~min}$ after wounding in etiolated tissue. Peak production varied from 1.6 to 24 times basal level in dark-grown seedlings. Non-etiolated woody tissue showed greater variation in the kinetics of wound-induced ethylene production, often had a longer lag (up to $55 \mathrm{~min}$ ), and displayed peak ethylene production times of 100-133 min. Based on these examples of the effect of stress on ethylene levels, ethylene measurement may be a useful tool for identifying conditions that impact plant growth.

Hydroponic systems provide an economical and viable alternative for the cultivation of strawberry, a

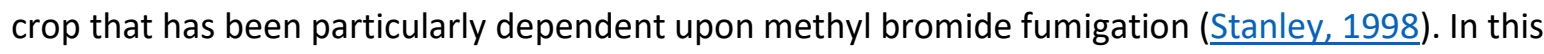
study, we demonstrate that assessing ethylene levels from leaves of hydroponically-grown strawberry plants is useful as an early indicator of stress conditions within the system. This method can be used to determine inconsistencies within a hydroponic system that may cause plant stress and affect subsequent plant growth and fruit production.

\section{Materials and methods}

\subsection{Hydroponics}

The strawberry growth conditions and hydroponic system design were developed in consultation with Dr. Fumiomi Takeda (USDA-ARS Appalachian Fruit Research Station, Kearneysville, West Virginia, USA) and adapted from the procedures described in Takeda (1999). Chandler strawberries (Fragaria $x$ ananassa), a short-day (SD) cultivar, were purchased as plants (Davon Crest Farm, Maryland, USA) or grown from runners (Strawberry Tyme Farms, Ontario, Canada). Prior to planting in the hydroponic systems, runners and plants received a cold treatment of $4{ }^{\circ} \mathrm{C}$ in a refrigerator for 6 weeks to stimulate 
flowering. Runners were rooted under a misting bench. Rooted runners or plants were planted in commercial peat-based soilless planting mixture (Premier Horticulture Inc., Red Hill, Pennsylvania, USA) within $15.24 \mathrm{~cm}$ circular net pots. Pots were placed in Hydroware ${ }^{\mathrm{TM}}$ trays $(1.06 \mathrm{~m}$ length $\times 0.203 \mathrm{~m}$ width $\times 0.102 \mathrm{~m}$ depth; Sea of Green, Tempe, Arizona, USA), lined with plastic screening, and surrounded by sifted perlite. White-on-black plastic mulch (Garden Indoors, Columbus, Ohio, USA) was placed over the perlite and around the plants to control evaporation and algal growth. A nutrient solution of 5N-11P-26K fertilizer (Scotts HydroSol Water Soluble Fertilizer) supplemented with $0.18 \mathrm{~g} \mathrm{l}-1$ Epson salts (MgSO4), $0.64 \mathrm{~g} \mathrm{I}-1 \mathrm{CaNO}$, and $0.015 \mathrm{~g} \mathrm{I}-1 \mathrm{FeCl} 3$ at pH 6.2 was changed every 710 days to maintain nutrient concentrations, regulate $\mathrm{pH}$, and minimize salt accumulation.

Each hydroponic system consisted of 10 trays containing three plants each ( 30 plants total), connected to a central nutrient delivery pipe (Fig. 1). A submersible fountain pump was located in a 55 I container, and the nutrient solution was circulated through a central pipe that was attached to $1.3 \mathrm{~m}$ of irrigation drip tape per tray with $10 \mathrm{~cm}$ emitter spacing (RO-DRIP, Roberts Irrigation Products, San Marcos, CA). The drip tape lay over the perlite and pots and under the plastic mulch of each tray. Pressure in the central delivery pipe and the attached drip tape was controlled by a valve adjacent to the tray farthest from the pump so that the drip tape was completely expanded over all trays to deliver $5 \mathrm{Ih}-1 \mathrm{~m}-1$. Troughs were inclined to approximately a $15^{\circ}$ angle to aid drainage, with the higher end located at the central delivery pipe. Excess solution from the central delivery pipe and from each tray was returned by gravity back to the main 55 I reservoir. No pesticides were used.

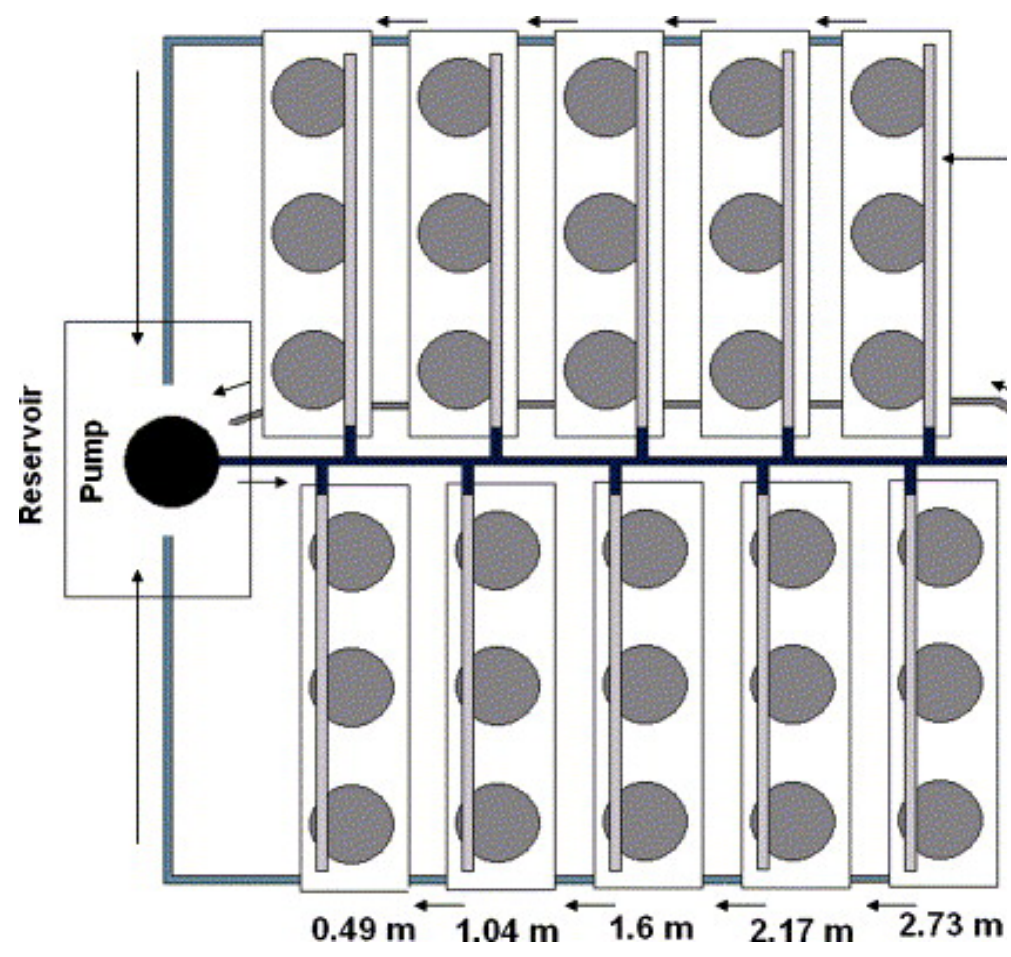

Fig. 1. Schematic representation of hydroponic system design showing 10 trays (rectangles) containing three pots each (shaded circles). The black circle represents the nutrient pump; arrows indicate nutrient flow direction. The open circle shows the location of the valve that controls the rate of the return flow 
to the pump located within the 55 I reservoir (large rectangle). This diagram also shows the relative distance of each tray from the pump (values across bottom), distances of individual plants from the central nutrient delivery pipe (values at right), and positioning of the drip tape (narrow shaded rectangles) over each pot. White-on-black plastic mulch covered each tray, and the drip tape, in the final assembly.

Plants were allowed to acclimate to the hydroponic systems for a minimum of 2 weeks prior to experimentation. Experiments were conducted under natural SD photoperiod, supplemented by highpressure sodium lights. During daylight hours, light intensity ranged from 63 to $1500 \mu \mathrm{mol} m-2 \mathrm{~s}-1$ photosynthetic active radiation (PAR). Greenhouse temperatures ranged between 15 and $37^{\circ} \mathrm{C}$ during these experiments.

\subsection{Ethylene measurements}

The kinetics of wound-induced ethylene production were determined in excised strawberry leaflets in order to establish the basal and peak wound-induced ethylene levels for this tissue. To evaluate woundinduced ethylene production, excised leaflets ( $0.25-0.5 \mathrm{~g}$ fresh weight each) were wounded (cut into sections), placed in $2 \mathrm{ml}$ vials, and capped. Headspace around leaflets in vials was sampled at $20 \mathrm{~min}$ intervals; vials were aired for $0.5 \mathrm{~min}$ before they were re-capped for the next sampling interval. A $1.0 \mathrm{ml}$ headspace sample was injected onto an alumina F1 column $(0.635 \mathrm{~cm} \times 0.91 \mathrm{~m})$ in a gas chromatograph (Varian 3700, Varian Instrument Division, Walnut Creek, California, USA) equipped with a flame ionization detector according to the procedure described by Harrison (1997). The nitrogen carrier gas flow rate was $40 \mathrm{ml} \mathrm{min}-1$ and the oven temperature was maintained at $100{ }^{\circ} \mathrm{C}$. Hydrogen and air flow rates to the detector were 40 and $300-400 \mathrm{ml} \mathrm{min-1,} \mathrm{respectively,} \mathrm{and} \mathrm{the} \mathrm{detector}$ temperature was set at $150^{\circ} \mathrm{C}$. Known amounts of an ethylene standard (Scott Specialty Gases, Plumsteadville, Pennsylvania, USA) were analyzed to produce a standard curve for ethylene quantitation.

Flooding stress was evaluated in leaflets from plants in which trays were flooded continuously for $72 \mathrm{~h}$, and then drained. Following the procedure above, ethylene measurements were taken from excised leaflets before flooding, at $24 \mathrm{~h}$ intervals during flooding, and $24 \mathrm{~h}$ after the trays had been drained. For system-wide ethylene analyses, ethylene production was measured according to the above method from one leaflet (0.1-0.5 g fresh weight) of each plant within a system. Each vial containing a leaflet was capped with a rubber septum for 20 min to allow accumulation of ethylene at room temperature. This time interval was chosen based on experimental data showing that no significant wound-induced ethylene production was yet occurring.

\subsection{System-wide experiments}

System-wide analyses of ethylene production were conducted for all plants within four hydroponic systems in order to evaluate the effect of daily fluctuations in light intensity and temperature associated with greenhouse growth conditions. A total of six analyses were conducted in February and March of 2002 and in February 2003 to establish basal ethylene production and identify potentially stress-induced plants within each system. In 2003, system-wide analysis of ethylene production was accompanied by measurements of flower and flower bud number, inflorescence number, crown number, and plant radius. In addition, flooding stress was evaluated in terms of its effect on plant productivity. For this experiment, five trays on the same side of the system were filled with water for $24 \mathrm{~h}$. Growth and yield 
parameters comparing the flooded to the well-drained control trays ( 15 plants per treatment) were measured at the time of flooding and at 1 and 2 months after the treatment ended.

\subsection{Statistical analysis}

Significance between the means was determined by one-way ANOVA (Microsoft Excel) to evaluate differences in groups of plants. Levels of significance are represented by $* P<0.05$. Regression analysis was used to determine significant correlation $\left({ }^{*} P<0.05\right)$ between light intensity or temperature with ethylene production (Microsoft Excel).

\section{Results}

The measurements of wound-induced ethylene showed a significant increase in ethylene production by 40-60 min after wounding (Fig. 2) and reached peak ethylene production by 120-140 min after wounding. Flooding increased ethylene production to twice the basal level within $48 \mathrm{~h}$ after flooding and more than three times basal level by $72 \mathrm{~h}$ of flooding. Ethylene production remained higher even $24 \mathrm{~h}$ after the trays were drained $(P=0.02)$. Based on these data, ethylene values of twice or more the basal level were selected as potential stress-induced ethylene production in plants within hydroponic systems.

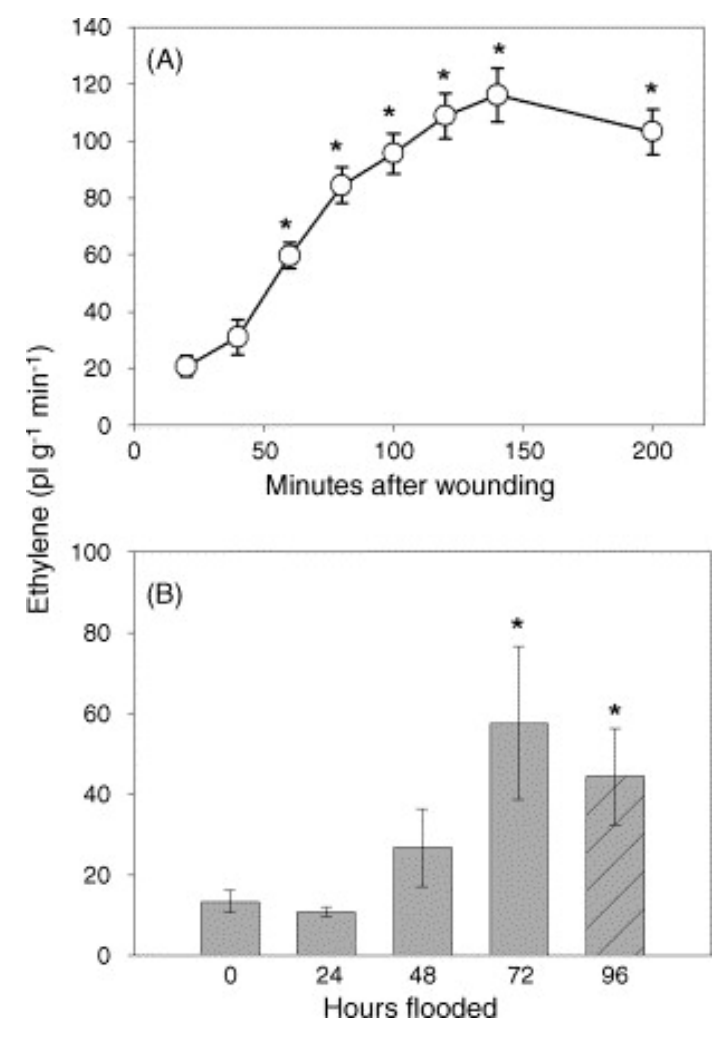

Fig. 2. (A) Kinetics of wound-inducible ethylene production by strawberry leaflets. Data points represent the average rate of ethylene accumulation for the $20 \mathrm{~min}$ interval prior to the point. (B) The effect of flooding on ethylene production by strawberry leaflets. The entire root system was submerged for $72 \mathrm{~h}$ 
(shaded bars), then drained and re-sampled after $24 \mathrm{~h}$ (hatched bar). Means + S.E. ( $\mathrm{n}=10$ plants).

$* P<0.05$ compared to the initial time point.

System-wide analyses were performed to determine whether stress-induced ethylene production could be identified independent of variances caused by temperature and light fluctuations. System analysis 4 , measured over a 9-day interval, showed no significant correlation between ethylene production and temperatures ranging from 18 to $30^{\circ} \mathrm{C}(P=0.39)$ or with light intensities ranging from 63 to $1075 \mu \mathrm{mol} \mathrm{m}-2 \mathrm{~s}-1 \mathrm{PAR}(\mathrm{P}=0.18$ ) (Fig. $3 \mathrm{~A}$ and $\mathrm{B}$ ). For this system, the average ethylene production was $20.3 \mathrm{pl} \mathrm{g-1} \mathrm{min-1,} \mathrm{which} \mathrm{was} \mathrm{used} \mathrm{to} \mathrm{represent} \mathrm{the} \mathrm{basal} \mathrm{level} \mathrm{(Table} \mathrm{1).} \mathrm{Two} \mathrm{plants} \mathrm{showed} \mathrm{potential}$ stress-induced ethylene levels of 44 and $89 \mathrm{pl} \mathrm{g-1} \mathrm{min-1} \mathrm{(Fig.} 3 \mathrm{~A}$ and B). Both plants were located in the farthest position from the central delivery pipe. The ethylene levels from these plants also contributed to higher averages for plants positioned at 0.49 and $1.6 \mathrm{~m}$ from the nutrient pump (Fig. $3 \mathrm{D}$ ). Additional measurements gathered 1 month later (system analysis 5 ) showed system-wide average ethylene levels that were approximately twice as high as the earlier measurements, averaging $42.1 \mathrm{pl} \mathrm{g-1} \mathrm{min-1.}$ Nonetheless, there was no significant correlation with light intensity or temperature.
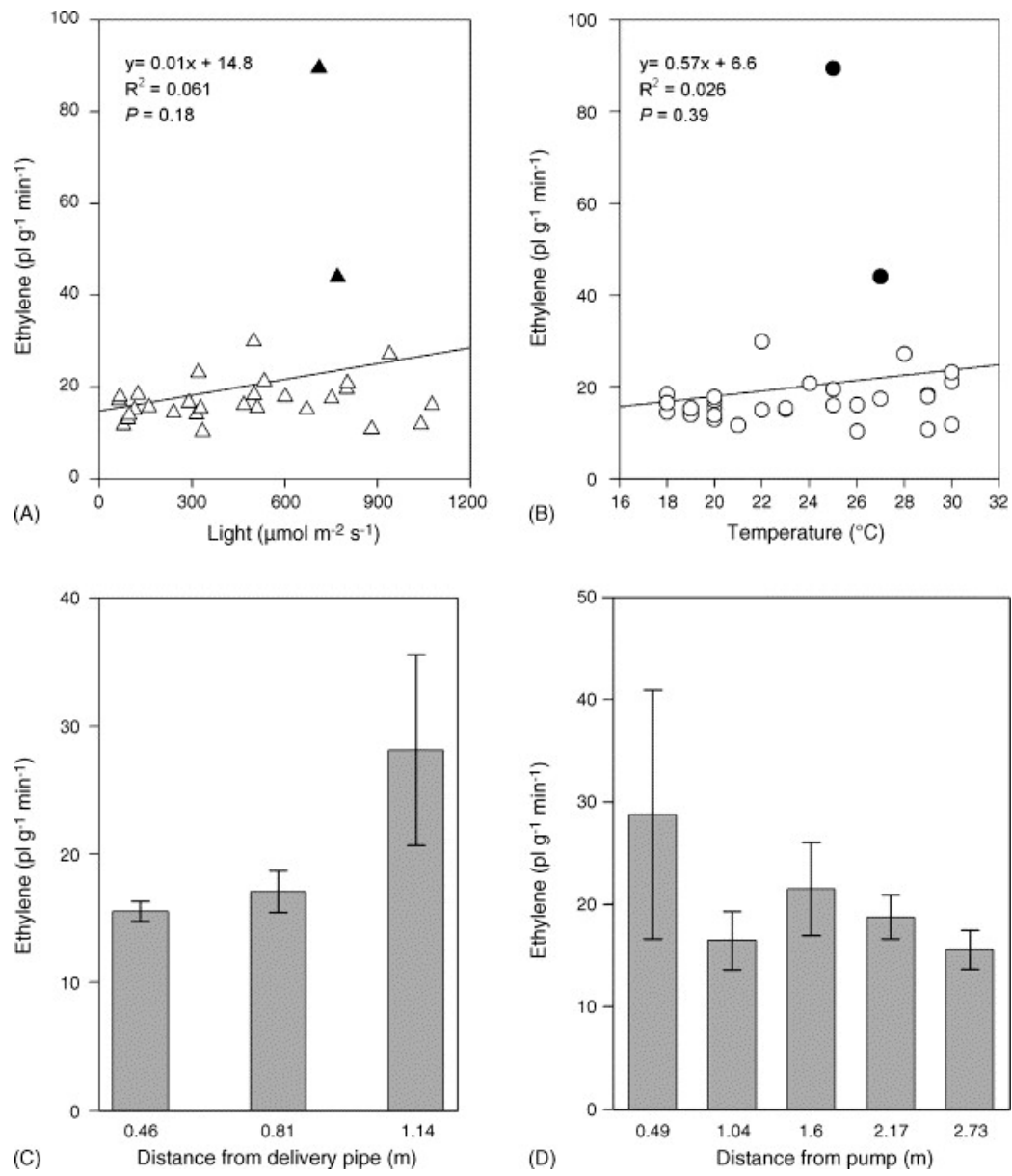

Fig. 3. Ethylene measurements from strawberry leaflets for system analysis 4. (A) Evaluation of light intensity on foliar ethylene production. Light intensities below $100 \mu \mathrm{mol} m-2 \mathrm{~s}-1$ PAR indicate measurements taken at or after dusk. Filled symbols represent plants exhibiting potential stress-induced 
ethylene production. (B) Evaluation of temperature variations on foliar ethylene production. Filled symbols represent plants exhibiting potential stress-induced ethylene production. (C) Evaluation of ethylene production from plants at different positions from the central delivery pipe. (D) Evaluation of ethylene production from plants at different positions from the pump. For (C) and (D), vertical bars indicate standard error of the mean for 30 samples.

Table 1. Correlation between light or temperature and ethylene production ( $p l$ g-1 min-1) for individual plants in systems built in 2002

System analysis number (dates measured in 2002)

$1(2 / 5,2 / 7,2 / 14,2 / 15)$

$2(2 / 22,2 / 28,3 / 1)$

$3(3 / 28)$

$4(3 / 5,3 / 12,3 / 14)$

$5(3 / 27,3 / 28)$
Ethylene

(pl g-1 min-1)
Light ( $\mu \mathrm{mol}$ m-2 s-1

PAR)

Range Average R2 Range Average R2

$27.2 \pm 1.64$

$28.5 \pm 1.35$

$28.7 \pm 1.66$

$20.3 \pm 0.85$

$42.1 \pm 2.87$
0.128

$15-$

37

$25.1 \quad 0.008$

$\begin{array}{llllll}338- & 895 & 0.023 & \begin{array}{l}15- \\ 35\end{array} & 24.5 & 0.083\end{array}$

$1-582 \quad 200$

$0.442 *-26$

21.7

0.063

63-1075 453

$0.061 \begin{array}{lll}18- \\ 30\end{array} 23.6 \quad 0.026$

$165-$

1467

827

$0.093 \begin{aligned} & 20- \\ & 29\end{aligned} 25.4 \quad 0.017$
$1-740 \quad 299$

These measurements demonstrate that there was no correlation between ethylene production and light intensity or temperature at the $\mathrm{P}<0.05$ level.

$*$

$\mathrm{P}<0.05$.

All system-wide analyses of ethylene production are summarized in Tables 1-3. In general, these results show that ethylene levels were not significantly affected by temperature and light changes under greenhouse conditions. However, an increase in ethylene tended to be positively correlated with increases in light and temperature for all systems, in a pattern similar to that shown in Fig. $3 \mathrm{~A}$ and B. A significant positive correlation was measured for system analysis 3 . These measurements were taken when light intensity ranged from $582 \mu \mathrm{mol} \mathrm{m}-2 \mathrm{~s}-1$ PAR in the afternoon to less than $1 \mu \mathrm{mol} \mathrm{m}-2 \mathrm{~s}-1$ PAR after sundown. The results suggest a relationship between ethylene production and the sampling time. To evaluate this effect, baseline ethylene values (omitting individual plants exhibiting stressinduced ethylene) were grouped according to time of analysis (Fig. 4). Ethylene production was significantly higher in plants sampled in midday (1200-1459) compared to those sampled in the morning (900-959) or early evening (1700-1859) ( $P=0.018$ and 0.027 , respectively). While these baseline levels showed fluctuations that averaged from 15.40 to $23.9 \mathrm{pl} \mathrm{g-1} \mathrm{min-1,} \mathrm{the} \mathrm{values} \mathrm{were} \mathrm{well} \mathrm{below} \mathrm{those}$ designated as stress-induced. Also, these data indicate that the significant correlation with light was a 
result of the sampling regime, which spanned late afternoon until after dusk. There was no observable trend when comparing ethylene production with the dates of measurement (Table 1).

Table 2. Comparison of ethylene production ( $\mathrm{pl} \mathrm{g-1} \mathrm{min-1)} \mathrm{for} \mathrm{plants} \mathrm{in} \mathrm{various} \mathrm{positions} \mathrm{from} \mathrm{the}$ delivery pipe for systems built in 2002 (system analyses 1-5) and 2003 (system analysis 6)

System analysis number

Ethylene (pl g-1 min-1)

$0.46 \underline{a}$

$0.81 \underline{a}$

$1.14 \underline{a}$

1

$23.3 \pm 8.7$

$41.8 \pm 16.3$

$16.3 \pm 2.1$

2

$25.1 \pm 2.06$

$34.9 \pm 4.7 \pm$

$25.6 \pm 5.35$

3

$28.1 \pm 15.3$

$24.9 \pm 5.8$

$33.1 \pm 8.5$

4

$15.4 \pm 0.8$

$17.1 \pm 1.6$

$28.1 \pm 7.4 \pm$

5

$39.9 \pm 11.4$

$32.8 \pm 3.3$

$53.7 \pm 14.4$

6

$16.6 \pm 4.6$

$17.3 \pm 3.1$

$16.7 \pm 2.5$

Values represent means + S.E. $(n=30)$

a

Distance from central delivery pipe $(\mathrm{m})$.

$+$

$\mathrm{P}<0.1$ compared to the average for the $0.46 \mathrm{~m}$ position.

Table 3. Comparison of ethylene production for plants in various positions from the pump for system analyses 1-6

System analysis number Ethylene production ( $\mathrm{plg}$ g-1 min-1)

$\begin{array}{llllll} & 0.49 \underline{a} & 1.04 \underline{a} & 1.6 \underline{a} & 2.17 \underline{a} & 2.73 \underline{a} \\ 1 & 18.1 \pm 3.7 & 30.9 \pm 9.0 & 34.0 \pm 12.6 & 40.8 \pm 28.1 & 12.0 \pm 1.3+ \\ 2 & 35.2 \pm 7.3 & 23.1 \pm 3.0 & 35.0 \pm 8.6 & 28.8 \pm 1.5 & 20.6 \pm 3.4^{*} \\ 3 & 43.6 \pm 24.5 & 22.4 \pm 5.9 & 34.2 \pm 11.6 & 14.7 \pm 2.5 & 28.4 \pm 12.4 \\ 4 & 28.8 \pm 12.1 & 16.5 \pm 2.5 & 21.5 \pm 4.5 & 18.7 \pm 2.2 & 15.6 \pm 1.9 \\ 5 & 49.7 \pm 21.5 & 45.5 \pm 10.5 & 37.4 \pm 4.8^{*} & 58.5 \pm 20.3 & 20.9 \pm 2.7^{*} \\ 6 & 12.6 \pm 3.2 & 10.3 \pm 1.9 & 17.6 \pm 2.2 & 18.1 \pm 3.8 & 25.6 \pm 7.2+\end{array}$

Values represent means + S.E. $(n=30) .+P<0.1$ and $* P<0.05$ increased compared to the averages for at least two of the previous positions. 
Distance from pump (m).

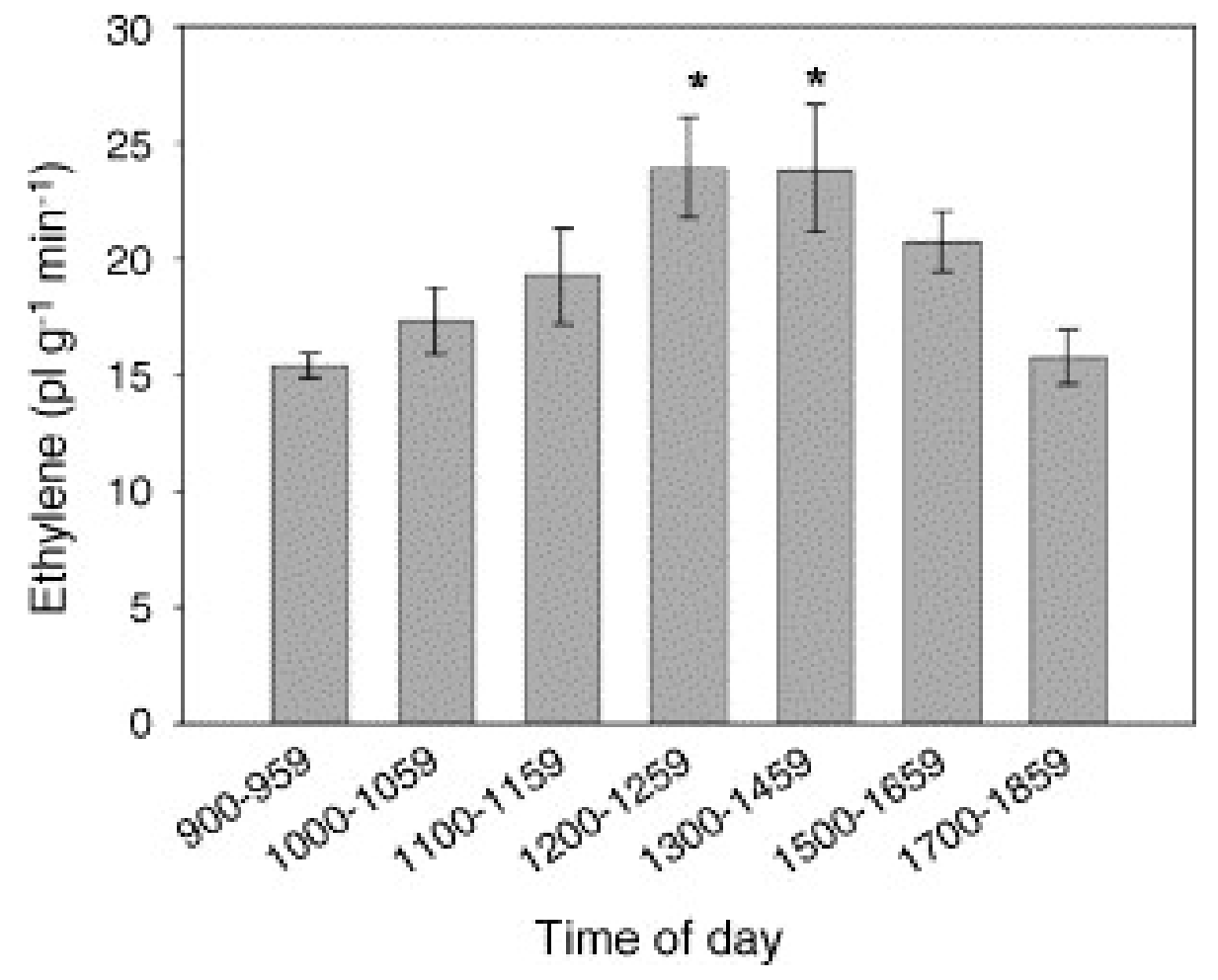

Fig. 4. Assessment of ethylene production at different sampling times. Plants were grouped according to sampling time, omitting those exhibiting potential stress-induced ethylene levels. Means + S.E. ( $n=13-$ 28 plants per group). ${ }^{*} \mathrm{P}<0.05$ for averages at the $1200-1259$ and $1300-1459$ intervals compared to averages at the 900-959 and 1700-1859 intervals.

Overall, three of the system-wide measurements (system analyses 2, 3, and 5) exhibited higher ethylene production in plants closer to the pump compared to the plants at the $2.73 \mathrm{~m}$ position; this increase was significant in system analyses 2 and $5(P<0.05$, see Table 3$)$. In system analysis 5 , ethylene production was significantly higher at the 1.04 and $1.6 \mathrm{~m}$ positions from the pump $(P=0.03$ and 0.01 , respectively) compared to plants located in the $2.73 \mathrm{~m}$ position, and highest in plants farthest from the delivery pipe (Tables 2 and 3 ). System analysis 6 showed increased ethylene production for the position farthest $(2.73 \mathrm{~m})$ from the pump, indicating a potential stress condition at that location $(P=0.06$; Table 3$)$. These plants had fewer flowers and significantly reduced plant radii $(P=0.03)$ compared to the average for the system (Table 4). In addition, plants from the flooded trays showed a significant decrease in the number of leaves, flowers, and plant radii on month post-flooding, indicating a negative impact on yield for at least as long that long (Table 5). By 2 months post-flooding, the plants had recovered and did not exhibit significantly different growth parameters compared to the controls.

Table 4. Growth parameters measured on 3 February 2003 for strawberry plants in system analysis 6 


\begin{tabular}{llll} 
Growth parameter & Averages for entire system & \multicolumn{2}{c}{ Distance from pump } \\
& & $0.49 \mathrm{~m}$ & $2.73 \mathrm{~m}$ \\
Leaf number & $9.03 \pm 0.29$ & $10.00 \pm 1.00$ & $7.67 \pm 0.89$ \\
Flower number & $6.79 \pm 0.68$ & $6.67 \pm 2.18$ & $4.67 \pm 1.20$ \\
Inflorescence number & $3.67 \pm 0.29$ & $5.00 \pm 0.60$ & $3.00 \pm 0.30$ \\
Plant radius (cm) & $9.43 \pm 0.30$ & $8.67 \pm 0.67$ & $7.33 \pm 0.46_{-}^{*}$
\end{tabular}

Averages for all plants are compared to plants in positions 0.49 and $2.73 \mathrm{~m}$ from the pump. Values represent means + S.E. $(n=30$ for entire system).

$\mathrm{P}<0.05$ compared to the overall system average.

Table 5. Growth parameters for strawberry plants in control (C) compared to flooded (F) conditions Date Leaf number Inflorescence number Radius $(\mathrm{cm})$ (2003) (a)

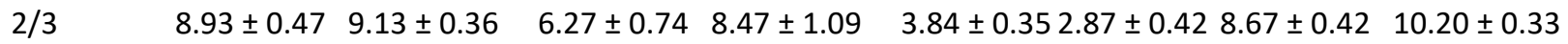

$3 / 10 \quad 16.80 \pm 1.4013 .07 \pm 0.69 * 18.67 \pm 1.3912 .67 \pm 0.85_{-}^{*} 3.00 \pm 0.262 .67 \pm 0.1913 .67 \pm 0.5111 .35 \pm 0.51_{-}^{*}$

$4 / 7 \quad 13.40 \pm 1.1512 .93 \pm 0.92 \quad 17.40 \pm 2.6418 .53 \pm 2.09 \quad 6.27 \pm 0.735 .93 \pm 0.5210 .80 \pm 0.5610 .91 \pm 0.71$

Half of system 6 was flooded (all five trays on the same side) for 24 h on 3 February 2003. Additional measurements were taken at approximately 1-month intervals. Values represent means + S.E. $(n=30)$.

$\mathrm{P}<0.05$ for plants from flooded trays compared to well-drained control plants.

4. Discussion

The reported data suggest that sampling time was a significant factor when evaluating ethylene

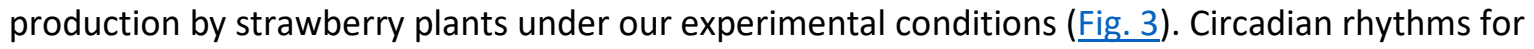
ethylene production have been reported for sorghum (Finlayson et al., 1998), cotton (Jasoni et al., 2000), and Arabidopsis thaliana (Thain et al., 2004). For these species, ethylene production peaks during midday and is lowest during the dark cycle, a rhythm that may reflect a midday temperature optimum for ethylene production. A temperature optimum of $30^{\circ} \mathrm{C}$ has been reported for ethylene production by apple fruit and mung been hypocotyls (Yu et al., 1980). Temperatures above $35^{\circ} \mathrm{C}$ often represent heatstress levels that inhibit ethylene production (Yu et al., 1980), however the temperature optimum and sensitivity to higher temperature is cultivar-dependent. For example, Balota et al. (2004) found increased ethylene production at temperatures as high as $38^{\circ} \mathrm{C}$ for wheat seedlings. In addition, Finlayson et al. (1998) found that while both light and temperature cycles were required to maintain 
circadian rhythm in sorghum, a SD plant, temperature cycles can override the light signal in controlling circadian ethylene production. Therefore, their results suggest a circadian rhythm and that fluctuation in temperature was likely the critical factor in regulating ethylene production. Since the average ethylene production values attributed to sampling time were lower than the values used to indicate stress conditions, we conclude that the high values observed for some plants were caused by an inherent stress to the plant rather than by a circadian rhythm. Also, the temperature range during the experimental time course did not reach heat-shock conditions, and no decline in ethylene production was observed at the higher temperatures. These data indicate that system-wide analysis should be conducted within a consistent time period to minimize differences due to a circadian effect.

For our system design, higher ethylene levels occurred in plants within areas that may have had inconsistencies in nutrient delivery or drainage pattern (manifested as pump pressure or drainage control by the valve on the delivery pipe). Higher flow rate may lead to excessive watering, which contributes to accumulation around the roots, especially for plants located at the lower end of the trays. However, the observed pattern of stress-induced ethylene production may represent an edge effect where plants along the perimeter receive more mechanical stimulation and show a wound-induced ethylene response. In system 4, plants that averaged an increase in ethylene also showed a decrease in flower number and plant radius, demonstrating ethylene analysis as a method for predicting negative impacts on yield (Table 4). When plants were flooded over a period of time, ethylene production increased in a manner consistent with increased ethylene levels observed in flooded tomato plants (English et al., 1995). Hypoxic conditions negatively affect the yield in horticulturally-important crops grown hydroponically (Urrestarazu and Mazuela, 2005). Urrestarazu and Mazuela (2005) report than even small changes in oxygen can be limiting for crops such as sweet pepper and melon, and note that increasing oxygen content by supplying an oxygen generator (potassium peroxide) through fertigation increased yield in these plants. They conclude that daily changes in oxygen content and watering level may be subtle, but could reflect a significant change in yield over the life of the plants. Our results suggest that measurements that indicate increased ethylene production may reflect inconsistencies within the system, such as reduced oxygen to the roots, that could then be evaluated and adjusted to increase overall crop yield.

This type of system-wide ethylene analysis has potential as a general indicator of stress for any hydroponically-grown crop and for many conditions that effect plant growth, such as insufficient watering, extreme temperature changes, wounding, or insect damage. While our systems were not treated with pesticide and the plants remained pest-free for the duration of the experiments, other plants infested with white flies exhibited greatly increased ethylene production (data not shown). Insect infestation can be observed visually, however, the use of ethylene measurements serves to assess the earliest stress effect before a change in plant growth and flowering can be observed.

In conclusion, system-wide ethylene measurements can be used to indicate stressed plants within hydroponic systems. This type of analysis would be especially useful as an indicator of general stress conditions no matter the cause, identifying locations that may result in lower plant productivity. Plants with higher ethylene levels can then be examined for the cause and appropriate management adjustments (nutrient delivery, pest control, etc.) made. Our data imply that system-wide analysis would best be performed over a short time interval to minimize differences due to natural circadian fluctuations in ethylene production. 


\section{Acknowledgements}

We wish to thank Dr. Fumiomi Takeda (USDA-ARS Appalachian Fruit Research Station, Kearneysville, West Virginia, USA) for advice on hydroponic system design and strawberry cultivation. We also thank Susan Weinstein for her careful reading and helpful advice concerning this manuscript. This research was supported by the NASA-EPSCoR West Virginia Space Grant Consortium.

Recommended articles

Citing articles (3)

References

\section{Abeles et al., 1992}

F.B. Abeles, P.W. Morgan, M.E. SaltveitEthylene in Plant Biology

(2nd ed.), Academic Press Inc., San Diego, California (1992)

Balota et al., 2004

M. Balota, S. Cristescu, W.A. Payne, S. te Lintel Hekkert, L.J.J. Laarhoven, F.J.M. HarrenEthylene production of two wheat cultivars exposed to desiccation, heat, and paraquat-induced oxidation

Crop Sci., 44 (2004), pp. 812-818

\section{Carpenter et al., 2000}

Carpenter, J., Gianessi, L., Lynch, L., 2000. The economic impact of the scheduled U.S. phaseout of methyl bromide. National Center for Food and Agricultural Policy Report, http://www.ncfap.org/reports/pesticides/methyl bromide/mb.pdf.

\section{Druege, 2006}

Druege, U., 2006. Ethylene and plant responses to abiotic stress. In: Khan, N.A. (Ed.), Ethylene Action in Plants. Springer-Verlag, Berlin, pp. 81-118.

\section{English et al., 1995}

P.J. English, C.W. Lycett, J.A. Roberts, M.B. JacksonIncreased 1-aminocyclopropane-1-carboxylic acid oxidase activity in shoots of flooded tomato plants raises ethylene production to physiologically active levels

Plant Physiol., 109 (1995), pp. 1435-1440

\section{Environmental Protection Agency, 1997}

Environmental Protection Agency, 1997. Hydroponics and soilless cultures on artificial substrates as an alternative to methyl bromide soil fumigation. In: Methyl Bromide Alternatives Case Studies, vol. 3. EPA 430-R-97-030, http://www.epa.gov/spdpublc/mbr/casestudies/volume3/hydropn3.html. 
Federal Register, 2004. Protection of stratospheric ozone: process for exempting critical uses from the phaseout of methyl bromide, final rule. Federal Register 69, 76982-77009.

\section{Finlayson et al., 1998}

S.A. Finlayson, I.-J. Lee, P.W. MorganPhytochrome B and the regulation of circadian ethylene production in sorghum

Plant Physiol., 116 (1998), pp. 17-25

\section{Harrison, 1997}

M.A. HarrisonAnalysis of ethylene biosynthesis

W.V. Dashek (Ed.), Methods in Plant Biochemistry and Molecular Biology, CRC Press, Boca Raton (1997), pp. 153-164

\section{Jackson, 2002}

M.B. JacksonLong distance signalling from roots to shoots assessed: the flooding story

J. Exp. Bot., 53 (2002), pp. 175-181

Jasoni et al., 2000

R.L. Jasoni, J.T. Cothren, P.W. Morgan, D.E. SohanCircadian ethylene production in cotton

Plant Growth Regulat., 36 (2000), pp. 127-133

\section{Saltveit and Dilley, 1978}

M.E. Saltveit Jr., D.R. DilleyRapidly induced wound ethylene from excised segments of etiolated Pisum sativum L., cv. alaska. I. Characterization of the response

Plant Physiol., 61 (1978), pp. 447-450

\section{$\underline{\text { Stanley, } 1998}$}

D. StanleyHydroponic strawberries avoid soil pests

Agric. Res. Mag., 46 (1998), pp. 10-11

Takeda, 1999

F. TakedaOut-of-season greenhouse strawberry production in soilless substrate

Adv. Strawberry Res., 18 (1999), pp. 4-15

\section{Thain et al., 2004}

S.C. Thain, F. Vandenbussche, L.J.J. Laarhoven, M.J. Dowson-Day, Z.-Y. Wang, E.M. Tobin, F.J.M. Harren, A.J. Millar, D. Van Der StraetenCircadian rhythms of ethylene emission in Arabidopsis

Plant Physiol., 136 (2004), pp. 3751-3761 
Urrestarazu and Mazuela, 2005

M. Urrestarazu, P.C. MazuelaEffect of slow-release oxygen supply by fertigation on horticultural crops under soilless culture

Sci. Hort., 106 (2005), pp. 484-490

$\underline{\text { ArticlePDF (100KB) }}$

VanSickle et al., 2000

VanSickle, J., Brewster, C., Spreen, T., 2000. Impact of a methyl bromide ban on the U.S. vegetable industry. Agricultural Experiment Station Bulletin No. 333. University of Florida, Department of Food and Agricultural Economics.

Yu et al., 1980

Y.-B. Yu, D.O. Adams, S.F. YangInhibition of ethylene production by 2,4-dinitrophenol and high temperature

Plant Physiol., 66 (1980), pp. 286-290 